\title{
Reexploration Can Be Deterred by Point-of-Care Testing in Cardiac Surgery Patient
}

\author{
Vandana Bhardwaj ${ }^{1}$ Poonam Malhotra Kapoor ${ }^{1}$ \\ ${ }^{1}$ Department of Cardiac Anaesthesiology, Cardiothoracic \\ NeuroCenter, All India Institute of Medical Sciences, New Delhi, India \\ J Card Crit Care TSS 2017;1:48-50.
}

Hemostatic therapy based on point-of-care (POC) testing has been shown to reduce transfusion of blood products and decrease mortality associated with allogenic blood transfusion in cardiac surgery patients. ${ }^{1}$ We report a case of a 16 -year-old boy, planned for reexploration in view of continuous chest drain output (CDO), which was deterred by POC coagulation management.
Address for correspondence Vandana Bhardwaj, MD, DNB, Department of Cardiac Anaesthesiology, Cardiothoracic NeuroCenter, All India Institute of Medical Sciences, 7th Floor, New Delhi, India (e-mail: drvandana291@gmail.com).

A 16-year-old boy, weighing $47 \mathrm{~kg}$, underwent total correction for tetralogy of Fallot (TOF). The preoperative platelet count was $27,000 / \mathrm{mm}^{3}$, and prothrombin time/international normalized ratio (PT/INR) was 13.8/1.26. The POC baseline tests (T1) after induction of anesthesia were markedly deranged (-Figs. 1-3). The intraoperative period was uneventful with a cardiopulmonary bypass time of 108 minutes.

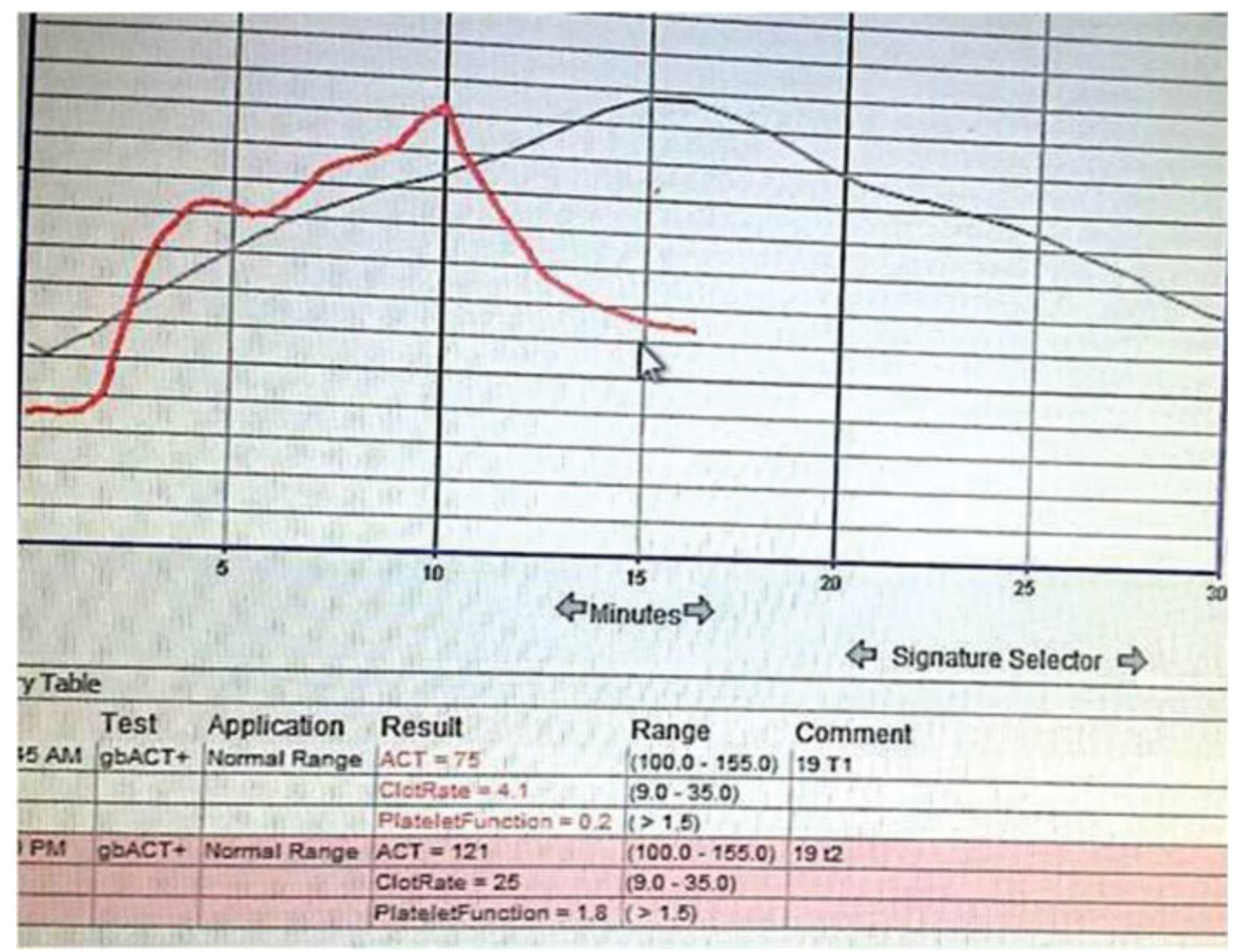

Fig. 1 Sonoclot signature before (black trace) and after transfusion of platelets, fresh frozen plasma, and cryoprecipitate (red). Clot rate increased from 4.1 to 25 , and platelet function improved from 0.2 to 1.8. ACT, activated clotting time; gbACT, glass bead activated clotting time.

DOI https://doi.org/ 10.1055/s-0037-1604173.
Copyright (c) 2017 Official Publication of License terms The Simulation Society (TSS), accredited by International Society of Cardiovascular Ultrasound (ISCU) 
A

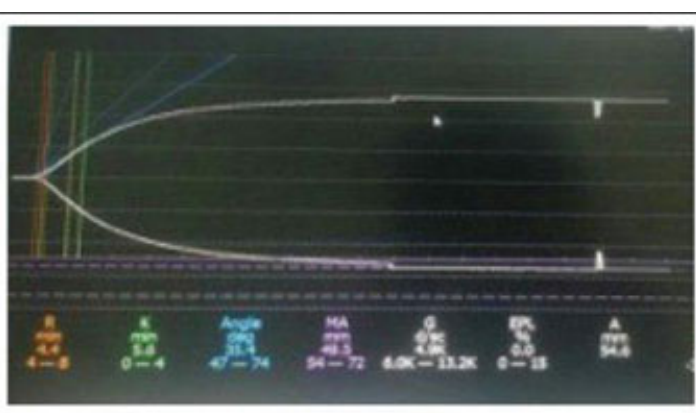

B

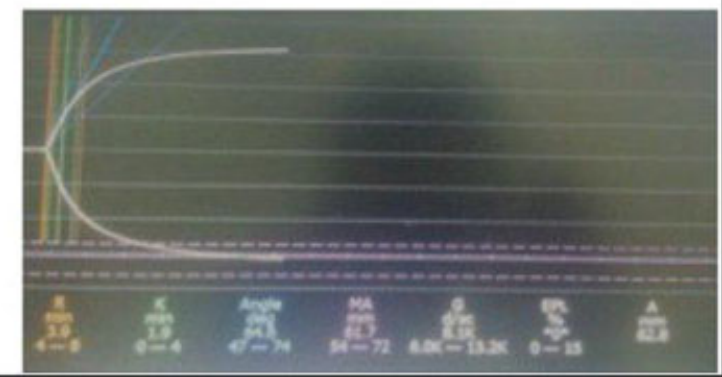

Fig. 2 (A) Thromboelastograph at baseline and after transfusion of blood products. (B) $\mathrm{K}$ value decreased from 5.6 to 1.9 and maximal clot amplitude increased from 49.5 to 61.7.
In post-bypass period, three units of a random donor platelet concentrate (PC) were transfused. The patient was shifted to intensive care unit (ICU) for elective ventilation. However, there was continuous CDO with $310 \mathrm{~mL}$ drain in the first 2 hours and $960 \mathrm{~mL}$ in the next 4 hours. The patient was transfused with 4 units of PC, 2 units of fresh-frozen plasma (FFP), 3 units of cryoprecipitate, and 1 unit of packed red blood cells (PRBC) to control bleeding and maintain hematocrit. The surgeons were planning reexploration, and in the meanwhile POC testing was performed. We observed a marked improvement in Sonoclot signature and thromboelastograph (TEG) (-Figs. 1, 2). The rotational thromboelastometry (ROTEM) parameters were showing improvement but were still deranged (-Fig. 3). In fifth postoperative hour CDO was $220 \mathrm{~mL}$. We transfused 5 units of cryoprecipitate and 4 units of FFP to control bleeding. The EXTEM and FIBTEM values got better ( - Fig. 3). In the next 3 hours, CDO was only $20 \mathrm{~mL}$ and the hemodynamics and hematocrit were maintained. The reexploration surgery was canceled. The patient was extubated after 8 hours and was discharged from ICU on fourth postoperative day.

The new POC devices correlate with standard laboratory coagulation tests and provide results in shorter turnaround time at bedside of the patient. ${ }^{2-4}$ The use of POC testing can

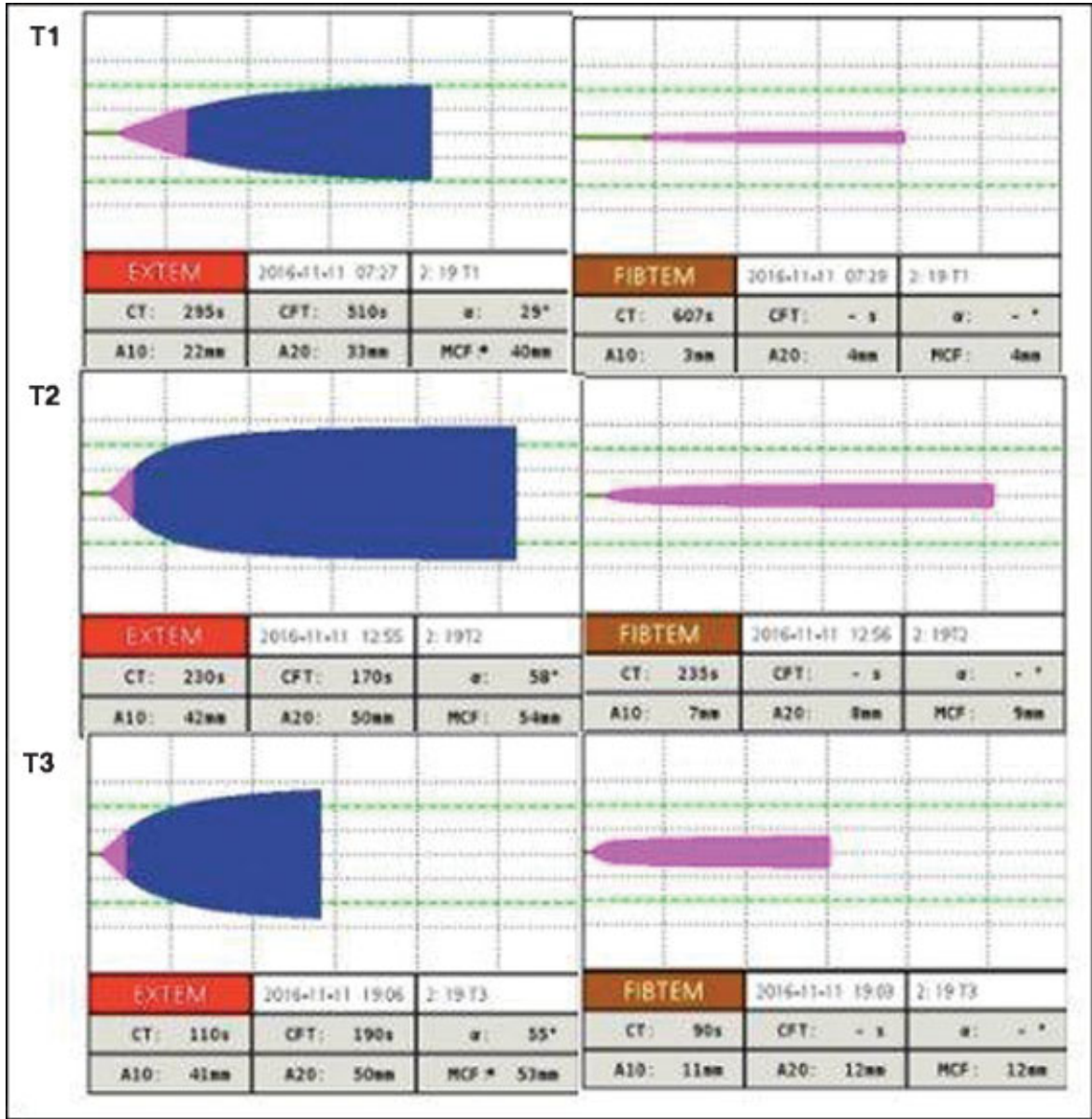

Fig. 3 Showing EXTEM, FIBTEM parameters of rotational thromboelastometry (ROTEM) before surgery (T1) and after 4 hours (T2) and 6 hours of surgery (T3). Note the improvement in EXTEM (clot time decreased from 290 to 110 seconds, maximal clot firmness increased from 40 to $53 \mathrm{~mm}$ ) and FIBTEM parameters (A20 increased from 4 to $12 \mathrm{~mm}$ ). 
differentiate surgical bleed from coagulopathy that can be managed by hemostatic therapy. This can reduce incidence of reexploration, morbidity, and hospital cost.

\section{References}

1 Weber CF, Görlinger K, Meininger D, et al. Point-of-care testing: a prospective, randomized clinical trial of efficacy in coagulopathic cardiac surgery patients. Anesthesiology 2012;117(03): 531-547
2 Olde Engberink RH, Kuiper GJ, Wetzels RJ, et al. Rapid and correct prediction of thrombocytopenia and hypofibrinogenemia with rotational thromboelastometry in cardiac surgery. J Cardiothorac Vasc Anesth 2014;28(02):210-216

3 Spalding GJ, Hartrumpf M, Sierig T, Oesberg N, Kirschke CG, Albes JM. Cost reduction of perioperative coagulation management in cardiac surgery: value of "bedside" thrombelastography (ROTEM). Eur J Cardiothorac Surg 2007;31(06):1052-1057

4 Gorlinger K, Bhardwaj V, Kapoor PM. Simulation in coagulation testing using rotational thromboelastometry: A fast emerging, reliable point of care technique. Ann Card Anaesth 2016;19(03): 516-520 